\title{
PERBANDINGAN JACCARD SIMILARITY DENGAN EXTENDED JACCARD SIMILARITY PADA PENALARAN BERBASIS KASUS
}

\author{
Murien Nugraheni ${ }^{1}$ \\ ${ }^{1}$ Prodi Sistem dan Teknologi Informasi, FT - UNJ \\ ${ }^{1}$ muriennugraheni@unj.ac.id
}

\begin{abstract}
Abstrak
Penalaran berbasis kasus memberikan solusi pada suatu kasus baru dengan menggunakan pengetahuan lalu yang tersimpan pada basis pengetahuan. Dilakukan perhitungan kasus baru dengan menggunakan sampel gejala yang akan didiagnosa dengan kasus lama yang telah tersimpan pada basis data. Kasus lama dengan nilai similaritas tertinggi akan diambil dan kemudian solusi dari kasus lama tersebut akan dijadikan solusi bagi kasus yang baru. Jika suatu kasus tidak berhasil didiagnosa, maka kasus tersebut akan dilakukan revisi oleh seorang pakar. Kasus yang berhasil direvisi akan disimpan ke dalam basis data untuk dijadikan pengetahuan baru.

Pada penelitian ini dilakukan dua perbandingan metode untuk menghitung tingkat kemiripan antara kasus baru dengan kasus lama. Metode similarity yang digunakan adalah metode Jaccard Similarity dan Extended Jaccard Similarity. Hasil dari penelitian ini diperoleh bahwa metode Extended Jaccard Similarity mempunyai tingkat kemiripan sebesar $52.6818 \%$ sedangkan metode Jaccard Similarity memiliki tingkat kemiripan sebesar $47.3181 \%$.
\end{abstract}

Kata kunci : Case-Based Reasoning, Jaccard Similarity, Extended Jaccard Similarity

\section{Pendahuluan}

Penalaran berbasis kasus merupakan penalaran komputer yang menggunakan pengetahuan lama untuk mengatasi permasalahan baru. Penalaran berbasis kasus memberikan solusi terhadap kasus baru dengan melihat kasus lama yang mempunyai kemiripan paling mendekati dengan kasus baru. Hal ini akan sangat bermanfaat karena dapat menghilangkan kebutuhan untuk mengekstrak model seperti yang dibutuhkan oleh sistem berbasis aturan. Selain itu, penalaran berbasis kasus juga dapat dimulai dari jumlah pengetahuan yang sedikit karena pengetahuan penalaran berbasis kasus dapat bertambah secara bertahap ketika sebuah kasus ditambahkan.

Proses mencari kedekatan atau kemiripan antara kasus baru dengan kasus lama untuk memperoleh solusi terhadap kasus baru pada penlaaran berbasis kasus dapat menggunakan berbagai macam metode, dimana metode ini akan mempengaruhi keberhasilan dari penalaran berbasis kasus. Beberapa metode yang dapat digunakan dalam mencari kedekatan atau kemiripan kasus baru dengan kasus lama adalah Jaccard Similarity dan Extended Jaccard Similarity. Metode ini mengkorelasikan dua objek variabel kontinue yang mempunyai hubungan linier diantara atribut pada suatu objek.

Penelitian yang dilakukan oleh Fatmayati (2017:70) membandingkan dua metode Extended Jaccard Coefficient (Tanimoto Coefficient) dan Euclidean Distance Similarity untuk mendiagnosa penyakit gigi dan mulut. Dengan menghasilkan tingkat akurasi sebesar 95,24\% untuk Extended Jaccard Coefficient dan tingkat akurasi sebesar 100\% untuk Euclidean Distance Similarity.

Nurdiana (2016:59) dalam penelitiannya membandingkan metode Cosine Similarity dengan Jaccard Similarity pada aplikasi pencarian terjemah Al-Qur'an dalam Bahasa Indonesia. Dari hasil penelitian yang dilakukan, metode Cosine Similarity menghasilkan kemiripan tertinggi sebesar $41 \%$ dari metode Jaccard Similarity yang hanya $19 \%$.

\section{Metode}

\subsection{Penalaran Berbasis Kasus}

Penalaran berbasis kasus merupakan metode dari sistem pendukung keputusan yang menghasilkan solusi yang dibutuhkan dengan persamaan dari pengalaman yang terdahulu. Metode ini terdiri dari mengacu kembali, menggunakan kembali, meninjau ulang dan mendalami kasus yang telah lalu. Memproses permasalahan yang diajukan dengan menggunakan solusi pada kasus sebelumnya yang memiliki persamaan. Proses tersebut akan menghasilkan solusi yang telah dikembangkan dan disesuaikan untuk mengatasi permasalahan.

Penalaran berbasis kasus dapat direpresentasikan sebagai suatu siklus proses yang dibagi menjadi empat sub proses (Aamodt dan Plaza, 1994), yaitu :

a. Retrieve yaitu mencari kasus-kasus sebelumnya yang paling mirip dengan kasus baru. 
b. Reuse yaitu menggunakan kembali kasus-kasus yang paling mirip tersebut untuk mendapatkan solusi untuk kasus yang baru.

c. Revise yaitu melakukan penyesuaian dari solusi kasus-kasus sebelumnya agar dapat dijadikan solusi untuk kasus yang baru.

d. Retain yaitu memakai solusi baru sebagai bagian dari kasus baru, kemudian kasus baru di-update ke dalam basis kasus.

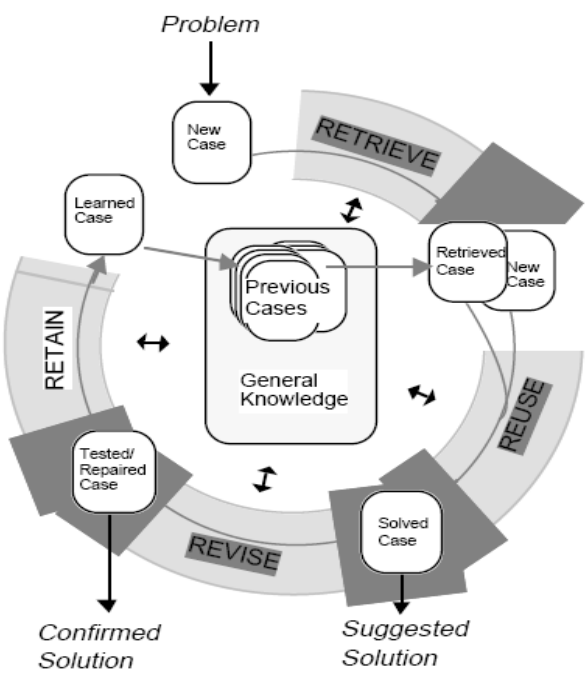

Gambar 1. Siklus Penalaran Berbasis Kasus (Source : Aamodt dan Plaza,1994)

Penalaran berbasis kasus menitikberatkan pemecahan masalah dengan didasarkan pada knowledge dari kasus-kasus sebelumnya, apabila ada kasus baru maka akan disimpan pada basis pengetahuan sehingga sistem akan melakukan learning dan knowledge yang dimiliki oleh sistem akan bertambah. Secara umum metode ini terdiri dari 4 langkah yaitu : 1) Retrieve

Pada proses ini adalah proses pengenalan masalah, yaitu dengan mengidentifikasi masalah yang baru.

2) Reuse

Dalam proses Reuse, sistem akan melakukan pencarian masalah terdahulu pada database melalui identifikasi masalah baru. Kemudian menggunakan kembali informasi permasalahan terdahulu tersebut yang memiliki kesamaan untuk menyelesaikan permasalahan yang baru.

3) Revise

Pada proses ini, informasi akan dievaluasi kembali untuk mengatasi masalah yang terjadi pada permasalahan baru. Kemudian sistem akan mengeluarkan solusi masalah baru.

4) Retain

Pada proses terakhir ini, sistem akan menyimpan permasalahan baru ke dalam knowledge-base untuk menyelesaikan permasalahan yang akan datang.

\subsection{Jaccard Similarity}

Salah satu cara untuk menghitung similaritas dua objek (items) yang bersifat biner adalah dengan menggunakan metode Jaccard Similarity.

Formula yang digunakan Jaccard Similarity untuk menghitung similaritas antara dua objek $\mathrm{x}$ dan y adalah sebagai berikut :

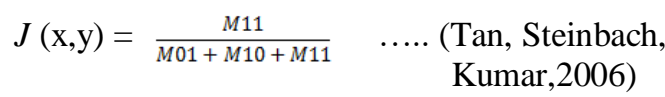

Keterangan :

$\mathrm{x} \quad$ : kasus lama

y : kasus baru

$\mathrm{M}_{11}$ : jumlah atribut biner dimana $\mathrm{x}=1$ dan $\mathrm{y}=1$

$\mathrm{M}_{10} \quad$ : jumlah atribut biner dimana $\mathrm{x}=1$ dan $\mathrm{y}=0$

$\mathrm{M}_{01} \quad$ : jumlah atribut biner dimana $\mathrm{x}=0$ dan $\mathrm{y}=1$

Kasus baru (y) adalah kasus yang akan dicari solusinya dengan cara membandingkan fitur gejala pada setiap kasus lama (x) atau kasus yang tersimpan di basis kasus. Kasus baru dikatakan similar (mirip) $100 \%$ dengan kasus yang lama apabila nilai similaritas dari $\operatorname{Jaccard}(\mathrm{x}, \mathrm{y})$ sama dengan 1 sedangkan tidak similar apabila nilai $\operatorname{Jaccard}(\mathrm{x}, \mathrm{y})$ sama dengan 0 .

\subsection{Extended Jaccard Similarity}

Extended Jaccard Coefficient atau yang sering disebut sebagai Tanimoto Coefficient adalah salah satu metode similaritas yang digunakan untuk melakukan perhitungan tingkat kemiripan dari dua buah objek.

Extended Jaccard Coefficient dapat di rumuskan sebagai berikut :

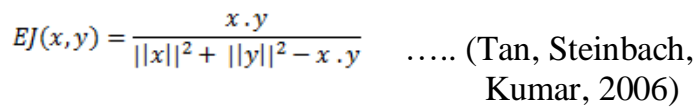

Dimana $\mathrm{x}$ adalah kasus lama dan y adalah kasus baru dan "\| \|" menunjukkan norm pada masing-masing vektor.

\section{Hasil dan Pembahasan}

\subsection{Representasi Kasus}

Secara umum, suatu kasus direpresentasikan dalam bentuk kumpulan fitur-fitur yang menjadi ciri kasus tersebut dan solusi untuk menangani kasus tersebut. Fitur-fitur yang disimpan merupakan parameter untuk mendapatkan solusi. Fitur-fitur tersebut bisa didapat dari akuisisi pengetahuan, dengan metode pengumpulan data studi pustaka.

Sebagai contoh pada perbandingan tingkat kemiripan suatu kasus dengan menggunakan dua metode similarity yang berbeda yaitu metode Jaccard Similarity dan metode Extended Jaccard Similarity dengan menggunakan 20 kasus yang telah tersimpan di dalam basis data untuk dilakukan perhitungan tingkat kemiripannya. 
Proses dimulai dengan melakukan perhitungan similarity kasus baru terhadap kasus lama. Proses perhitungan similarity menggunakan metode Jaccard Similarity dan Extended Jaccard Similarity. Nilai similarity yang digunakan yaitu 0 dan 1 . Dimana 0 menunjukkan tidak terlihat gejala yang muncul sedangkan nilai 1 menunjukkan bahwa gejala terlihat.

\subsection{Perhitungan Similaritas}

Terdapat 20 kasus dengan 9 gejala pada kasus lama yang tersimpan di dalam database.

Tabel 1. Contoh Representasi Kasus

\begin{tabular}{|c|c|c|c|c|c|c|c|c|c|}
\hline K & G1 & G2 & G3 & G4 & G5 & G6 & G7 & G8 & G9 \\
\hline 1 & 1 & 1 & 0 & 0 & 0 & 1 & 0 & 0 & 0 \\
\hline 2 & 1 & 0 & 1 & 0 & 0 & 1 & 0 & 0 & 0 \\
\hline 3 & 1 & 0 & 0 & 0 & 1 & 1 & 0 & 0 & 0 \\
\hline 4 & 1 & 0 & 0 & 0 & 0 & 0 & 1 & 0 & 0 \\
\hline 5 & 1 & 1 & 0 & 0 & 0 & 0 & 1 & 0 & 0 \\
\hline 6 & 1 & 0 & 1 & 0 & 0 & 0 & 1 & 0 & 0 \\
\hline 7 & 1 & 0 & 0 & 1 & 0 & 0 & 1 & 0 & 0 \\
\hline 8 & 1 & 0 & 0 & 0 & 1 & 0 & 1 & 0 & 0 \\
\hline 9 & 0 & 0 & 0 & 0 & 0 & 1 & 0 & 1 & 0 \\
\hline 10 & 0 & 0 & 0 & 0 & 0 & 1 & 0 & 0 & 1 \\
\hline 11 & 1 & 0 & 0 & 0 & 0 & 1 & 0 & 0 & 0 \\
\hline 12 & 0 & 1 & 0 & 0 & 0 & 1 & 0 & 0 & 0 \\
\hline 13 & 0 & 0 & 1 & 0 & 0 & 1 & 0 & 0 & 0 \\
\hline 14 & 0 & 0 & 0 & 1 & 0 & 1 & 0 & 0 & 0 \\
\hline 15 & 0 & 0 & 0 & 0 & 1 & 1 & 0 & 0 & 0 \\
\hline 16 & 0 & 1 & 0 & 0 & 0 & 0 & 1 & 0 & 0 \\
\hline 17 & 0 & 0 & 1 & 0 & 0 & 0 & 1 & 0 & 0 \\
\hline 18 & 0 & 0 & 0 & 1 & 0 & 0 & 1 & 0 & 0 \\
\hline 19 & 0 & 0 & 0 & 0 & 1 & 0 & 1 & 0 & 0 \\
\hline 20 & 0 & 0 & 0 & 0 & 0 & 0 & 1 & 0 & 0 \\
\hline
\end{tabular}

Tabel 2. Contoh Kasus Baru

\begin{tabular}{|l|l|l|l|l|l|l|l|l|l|}
\hline & G1 & G2 & G3 & G4 & G5 & G6 & G7 & G8 & G9 \\
\hline $\mathrm{y}$ & 1 & 0 & 0 & 1 & 0 & 1 & 0 & 0 & 0 \\
\hline
\end{tabular}

Akan diselesaikan menggunakan rumus untuk Jaccard Similarity sebagai berikut :

$\operatorname{Jaccard}(M)=\frac{M 11}{M 01+M 10+M 11}$

dimana :

$\begin{array}{ll}\mathrm{x} & \text { : kasus lama } \\ \mathrm{y} & \text { : kasus baru } \\ \mathrm{M}_{11} & \text { : jumlah atribut biner dimana } \mathrm{x}=1 \text { dan } \mathrm{y}=1 \\ \mathrm{M}_{10} & \text { : jumlah atribut biner dimana } \mathrm{x}=1 \text { dan } \mathrm{y}=0 \\ \mathrm{M}_{01} & \text { : jumlah atribut biner dimana } \mathrm{x}=0 \text { dan } \mathrm{y}=1\end{array}$

Sedangkan rumus Extended Jaccard Similarity adalah sebagai berikut :

$$
E J(x, y)=\frac{x \cdot y}{\|x\|^{2}+\|y\|^{2}-x \cdot y}
$$

Contoh perhitungan kasus 1 :

Kasus 1 merupakan nilai dari kasus lama (x) yang dibandingkan dengan kasus baru (y).

Tabel 3. Contoh Kasus 1

\begin{tabular}{|l|l|l|l|l|l|l|l|l|l|}
\hline Kasus 1 & 1 & 1 & 0 & 0 & 0 & 1 & 0 & 0 & 0 \\
\hline Kasus Baru (y) & 1 & 0 & 0 & 1 & 0 & 1 & 0 & 0 & 0 \\
\hline
\end{tabular}

Maka diperoleh :

$\mathrm{M} 01=1 ; \mathrm{M} 10=1 ; \mathrm{M} 11=2$

Sehingga

$\operatorname{Jaccard}(\mathrm{x}, \mathrm{y})=2 /(1+1+2)=2 / 4=0.5$

Untuk Extended Jaccard

$$
\begin{aligned}
(\mathrm{x}, \mathrm{y})= & {\left[\left(\mathrm{x}_{1}^{*} \mathrm{y}_{1}\right)+\left[\left(\mathrm{x}_{2} * \mathrm{y}_{2}\right)+\left[\left(\mathrm{x}_{3} * \mathrm{y}_{3}\right)+\left[\left(\mathrm{x}_{4} * \mathrm{y}_{4}\right)+\right.\right.\right.\right.} \\
& {\left[\left(\mathrm{x}_{5}^{*} \mathrm{y}_{5}\right)+\left[\left(\mathrm{x}_{6} * \mathrm{y}_{6}\right)+\left[\left(\mathrm{x}_{7} * \mathrm{y}_{7}\right)+\left[\left(\mathrm{x}_{8} * \mathrm{y}_{8}\right)\right]+\right.\right.\right.} \\
= & {[(1 * 1)+(1 * 0)+(0 * 0)+(0 * 1)+(0 * 0)+} \\
& (1 * 1)+(0 * 0)+(0 * 0)+(0 * 0)] \\
= & 1+0+0+0+0+1+0+0+0 \\
= & 2 \\
= & \sqrt{\mathrm{x}_{1}{ }^{2}+\mathrm{x}_{2}{ }^{2}+\mathrm{x}_{3}{ }^{2}+\mathrm{x}_{4}{ }^{2}+\mathrm{x}_{5}{ }^{2}+\mathrm{x}_{6}{ }^{2}+\mathrm{x}_{7}{ }^{2}+\mathrm{x}_{8}{ }^{2}+\mathrm{x}_{9}{ }^{2}} \\
= & \sqrt{1^{2}+1^{2}+0^{2}+0^{2}+0^{2}+1^{2}+0^{2}+0^{2}+0^{2}} \\
= & \sqrt{2} \\
= & (\sqrt{2})^{2}=2 \\
\|\mathrm{x}\|^{2}= & \sqrt{\mathrm{y}_{1}{ }^{2}+\mathrm{y}_{2}{ }^{2}+\mathrm{y}_{3}{ }^{2}+\mathrm{y}_{4}{ }^{2}+\mathrm{y}_{5}{ }^{2}+\mathrm{y}_{6}{ }^{2}+\mathrm{y}_{7}{ }^{2}+\mathrm{y}_{8}{ }^{2}+\mathrm{y}_{9}{ }^{2}} \\
\|\mathrm{y}\|= & \sqrt{1^{2}+0^{2}+0^{2}+1^{2}+0^{2}+1^{2}+0^{2}+0^{2}+0^{2}} \\
= & \sqrt{3} \\
= & (\sqrt{3})^{2}=3 \\
\mathrm{EJ}(\mathrm{x}, \mathrm{y})= & 2 / 2+3-2=2 / 3=0.667 \\
= &
\end{aligned}
$$

Hasil perhitungan similaritas dengan menggunakan Jaccard Similarity dan Extended Jaccard Similarity adalah sebagai berikut :

Tabel 4. Hasil Perhitungan Similaritas

\begin{tabular}{|c|c|c|}
\hline & Jaccard Similarity & $\begin{array}{c}\text { Extended Jaccard } \\
\text { Similarity }\end{array}$ \\
\hline Kasus 1 & 0.5 & 0.667 \\
\hline Kasus 2 & 0.5 & 0.667 \\
\hline Kasus 3 & 0.5 & 0.667 \\
\hline Kasus 4 & 0.25 & 0.25 \\
\hline Kasus 5 & 0.25 & 0.25 \\
\hline Kasus 6 & 0.25 & 0.25 \\
\hline Kasus 7 & 0.5 & 0.667 \\
\hline Kasus 8 & 0.25 & 0.25 \\
\hline Kasus 9 & 0.25 & 0.25 \\
\hline Kasus 10 & 0.25 & 0.25 \\
\hline Kasus 11 & 0.67 & 0.667 \\
\hline Kasus 12 & 0.25 & 0.25 \\
\hline Kasus 13 & 0.25 & 0.25 \\
\hline Kasus 14 & 0.67 & 0.667 \\
\hline Kasus 15 & 0.25 & 0.25 \\
\hline Kasus 16 & 0 & 0 \\
\hline Kasus 17 & 0 & 0 \\
\hline Kasus 18 & 0.25 & 0.25 \\
\hline Kasus 19 & 0 & 0 \\
\hline Kasus 20 & 0 & \\
\hline & & \\
\hline
\end{tabular}


Dari perhitungan 20 kasus didapatkan rataratanya yang kemudian dapat dilakukan perhitungan persentasenya untuk mendapatkan hasil perbandingan diantara kedua metode.

Rata-rata Jaccard Similarity : $\frac{5.84}{20}=0.292$ dan ratarata Extended Jaccard Similarity $: \frac{6.502}{20}=0.3251$

Persentase Jaccard Similarity :

$\frac{0.292}{0.6171} \times 100 \%=47.3181 \%$

Persentase Extended Jaccard Similarity :

$\frac{0.3251}{0.6171} \times 100 \%=52.6818 \%$

Metode Jaccard Similarity mempunyai persentase tingkat kemiripan sebesar $47.3181 \%$ dan metode Extended Jaccard Similarity mempunyai persentase tingkat kemiripan sebesar $52.6818 \%$.

\section{Kesimpulan dan Saran}

\subsection{Kesimpulan}

Dari hasil penelitian yang dilakukan didapat bahwa metode Extended Jaccard Similarity menghasilkan tingkat similaritas lebih tinggi dibandingkan dengan metode Jaccard Similarity yaitu sebesar $52.6818 \%$ untuk metode Extended Jaccard Similarity dan sebesar $47.3181 \%$ untuk metode Jaccard Similarity.

\subsection{Saran}

dilakukan :

Dari hasil penelitian ini diharapkan dapat

1 Perlu digunakan sampel data yang lebih banyak dan kompleks agar menghasilkan tingkat similaritas yang lebih akurat.

2 Perlu dilakukan perbandingan dengan menggunakan metode lain untuk menghasilkan tingkat kemiripan yang lebih tinggi.

Daftar Pustaka:

Fatmayati, Fryda. (2017). Implementasi Case Base Reasoning untuk Mendiagnosa Penyakit Gigi dan Mulut. Techno.COM. Vol. 16 No. 1. pp. 7079. Semarang.

Nurdiana, O., Jumadi, dan Nursantika, D. (2016). Perbandingan Metode Cosine Similarity dengan Metode Jaccard Similarity pada Aplikasi Pencarian Terjemah Al-Qur'an dalam Bahasa Indonesia. Jurnal Online Informatika. Vol. 1 No. 1. pp. 59-63. Bandung.

Aamodt, A. and Plaza, E. (1994). Case-Based Reasoning: Foundational Issues, Methodological Variations and System Approches. AICom-Artificial Intelligence Communications. IOS Press, Vol. 7: 1, pp.3959 .
Tan, P., Steinbach, M., Kumar, V. (2006). Intoduction To Data Mining. Boston: Pearson Education Inc. 